\title{
Early Communication Functioning of Infants with Cleft Lip and Palate
}

\author{
Alta Kritzinger, Brenda Louw and René Hugo \\ Centre for Early Intervention in Communication Pathology \\ Department of Communication Pathology \\ University of Pretoria
}

\begin{abstract}
.
This study investigated the early communication functioning and hearing abilities of 44 infants with cleft lip and palate, ages 3 to 31 months old. The results revealed that $64 \%$ of the subjects had a history of recurrent otitis media with effusion and $33 \%$ displayed associated anomalies. $26 \%$ of the subjects had mild hearing losses and middle ear pathology at the time of data collection. The subjects as a group displayed average developmental levels for perceptual-cognitive, socio-personal and receptive language skills, but a limited phonetic repertoire and a statistically significant expressive language delay. The results indicated that the subjects experienced a motor developmental delay, but this was not statistically significant. The implications for early communication intervention are to conduct regular hearing measurements and to conduct regular parent-centered therapy with individualized home programmes. Efforts should be directed towards expanding early communication intervention services to include all infants with cleft lip and palate in South Africa.
\end{abstract}

\section{OPSOMMING:}

Hierdie studie het ondersoek ingestel na die vroeë kommunikasie funksionering en gehoorvermoëns van 44 babas met gesplete lip en verhemelte, tussen die ouderdomme van 3 tot 31 maande. Volgens die resultate het $64 \%$ van die proefpersone 'n geskiedenis van herhaalde otitis media met effusie en 33\% het geassosieerde afwykings vertoon. 26\% van die proefpersone het ' $n$ geringe gehoorverlies en middeloor-patologie vertoon ten tye van data-insameling. Die proefpersone as groep het gemiddelde vlakke van ontwikkeling vertoon in die areas van perseptuele kognitiewe ontwikkeling, sosiaal persoonlike ontwikkeling en reseptiewe taalvaardighede. Hulle het egter 'n beperkte fonetiese repertoire en ' $n$ staties beduidende ekspressiewe taalagterstand vertoon. Alhoewel daar bevind is dat die proefpersone 'n motoriese ontwikkelingsagterstand vertoon het, is dit egter nie staties beduidend van aard nie. Die implikasies vir vroeë kommunikasie intervensie is om sulke babas se gehoor gereeld te monitor en om gereelde ouer gesentreerde terapie met geïndividualiseerde tuisprogramme uit te voer. Pogings moet aangewend word om uroeë kommunikasie intervensie dienste uit te brei om alle gesplete lip en verhemelte babas in Suid-Afrika in te sluit.

KEY WORDS: cleft lip and palate infants, risk factors, early communication development, early intervention.

Infants with cleft lip and palate are at-risk of developing communication delays or disorders not only due to the established risk of the cleft itself, but also due to biological and environmental risk factors during their critical period for language acquisition. Known biological risk factors which can negatively impact on the communication development of this population include associated anomalies and hearing impairment. Although hearing impairment relative to recurrent otitis media with effu. sion has been reported extensively (Goldman, Martinez \& Ganzel, 1993; Scheurle, 1989), the risk for sensorineural hearing impairment appears to be under reported. It is generally accepted that the presence of anatomical malformations of the head and neck, which includes the population with clefts, indicates a risk for all forms of hearing impairment (ASHA, 1994). One reason for the under reporting of sensorineural hearing loss could be that studies on the communication development of children with cleft lip and palate often exclude the cases with associated anomalies who could present with various forms of hearing impairment.

Environmental risk factors proposed to impact on the early development of infants with cleft lip and palate include early surgical intervention, disruption of parent-infant-interaction due to the trauma of the diagnosis, resulting in changes in early socialization, the effect of infant appearance on adult developmental expectations and family stress due to increased care giving needs of having an infant with a congenital malformation (Savage, Neiman \& Reuter, 1994).

The presence of multiple risk factors in infants with clefting conditions is indicative of a heterogenous population with the possibility of displaying a variety of developmental disorders. When applying the transactional view of etiology as described by Samerhoff (1986), another implication becomes clear. The effect of multiple risk factors 
early in life implies a complex reciprocal interaction over time between infants with cleft lip and palate and their environment, resulting in an ever-changing profile of their speech and language development. For example, the transactional interaction of biological risk factors within the infant with a cleft lip and palate can be seen as the physiological malformation of the speech and hearing mechanisms (Lynch, 1986) impacting on the neuromotor encoding and auditory decoding skills of the infant (Bzoch in Russell \& Grunwell, 1993), which may contribute to the speech and language delay evidenced in these infants. Intermittent attacks of otitis media as well as discrete environmental events such as surgery resulting in family stress, add to a developmental profile which changes not only as a result of development itself. The transactional view of etiology also explains why no single risk factor can be viewed as the cause of early delays in speech and lan-

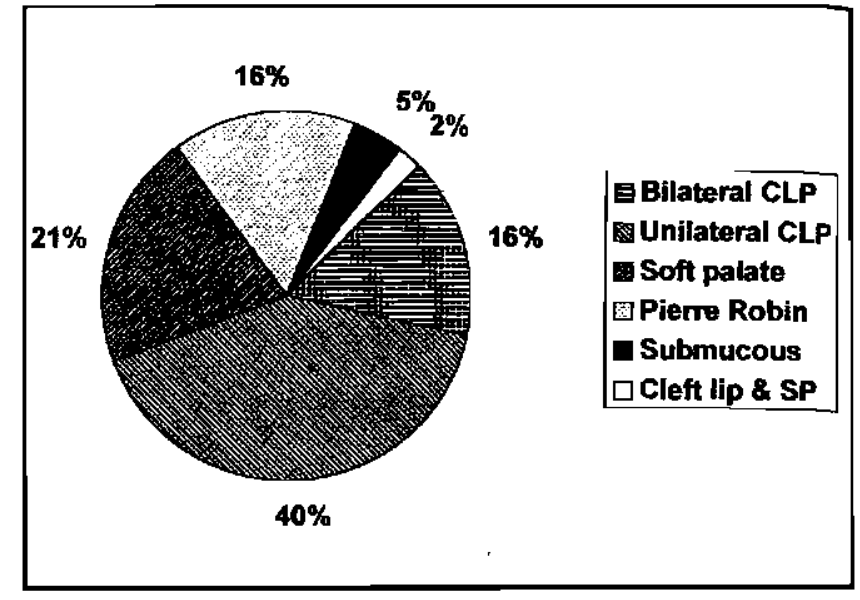

FIGURE 1: Differences in cleft types, $N=44$

TABLE 1. Description of Subjects, N=44

\begin{tabular}{|c|c|c|c|}
\hline Feature & \multicolumn{3}{|l|}{ Description } \\
\hline Age & \multicolumn{3}{|c|}{$\begin{array}{l}\text { Range: } 3 \text { to } 31 \text { months } \\
\text { Mean: } 15 \text { months }\end{array}$} \\
\hline Gender & \multicolumn{3}{|c|}{$\begin{array}{l}24 \text { subjects female }(54,5 \%) \\
20 \text { subjects male }(45,5 \%)\end{array}$} \\
\hline \multirow[t]{2}{*}{ Birthweight } & \multicolumn{3}{|c|}{$\begin{array}{l}\text { Pierre Robin Sequence, } \mathrm{N}=7 \\
\text { Range: } 2,25 \mathrm{~kg} \text { to } 4,25 \\
\text { Mean: } 2,94 \mathrm{~kg}\end{array}$} \\
\hline & \multicolumn{3}{|c|}{$\begin{array}{l}\text { All other subjects, } \mathrm{N}=37 \\
\text { Range: } 1,37 \mathrm{~kg} \text { to } 5 \mathrm{~kg} \\
\text { Mean: } 3,23 \mathrm{~kg}\end{array}$} \\
\hline Neonatal Intensive Care & \multicolumn{2}{|c|}{$\begin{array}{l}10 \text { subjects in incubator }(22,7 \%) \\
34 \text { subjects without intensive care } \\
(77,3 \%)\end{array}$} & 4 \\
\hline Feeding during neonatal period & \multicolumn{3}{|c|}{$\begin{array}{l}11 \text { subjects tube fed }(25 \%) \\
7 \text { subjects breastfed }(15,9 \%) \\
26 \text { subjects bottle fed }(59,1 \%)\end{array}$} \\
\hline $\begin{array}{l}\text { Associated conditions: } \\
\text { - Associated anomalies }\end{array}$ & \multicolumn{2}{|c|}{$\begin{array}{l}1 \text { subject with Down Syndrome } \\
1 \text { subject with sensorineural hearing } \\
\text { loss due to congenital syphilis }\end{array}$} & \\
\hline - Other physical defects & \multicolumn{2}{|c|}{$\begin{array}{l}1 \text { subject with heart defect } \\
1 \text { subject with bilateral polydactyly } \\
1 \text { subject with hernia }\end{array}$} & $\vdots$ \\
\hline - Low birthweight & \multicolumn{2}{|c|}{8 subjects $<2.5 \mathrm{~kg}(18,2 \%)$} & 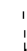 \\
\hline - Other biological risks & \multicolumn{2}{|c|}{1 subject one of a twin } & t \\
\hline Total: & \multicolumn{2}{|c|}{$\begin{array}{l}14 \text { subjects with associated conditions }(31.9 \%) \\
30 \text { subjects without associated conditions }(68,1 \%)\end{array}$} & \\
\hline \multirow[t]{2}{*}{ Age of cleft repair } & $\begin{array}{l}\text { Soft palate: } \\
\text { Mean: }\end{array}$ & $\begin{array}{l}3 \text { to } 23 \text { months } \\
5 \text { months }\end{array}$ & \\
\hline & $\begin{array}{l}\text { Lip and hard palate: } \\
\text { Mean: }\end{array}$ & $\begin{array}{l}6 \text { to } 9 \text { months } \\
7 \text { months }\end{array}$ & , \\
\hline $\begin{array}{l}\text { Pre-operative early } \\
\text { communication intervention (ECI) }\end{array}$ & \multicolumn{3}{|c|}{$\begin{array}{l}41 \text { subjects received ECI }(93,2 \%) \\
3 \text { subjects received no ECI }(6,8 \%)\end{array}$} \\
\hline $\begin{array}{l}\text { Socio-economic status } \\
3 \text { low income families }(6,8 \%)\end{array}$ & \multicolumn{3}{|c|}{41 middle income families $(93,2 \%)$} \\
\hline Geographical representation & \multicolumn{3}{|c|}{$\begin{array}{l}28 \text { living in Gauteng Province }(63,6 \%) \\
16 \text { living outside Gauteng Province }(36,4 \%)\end{array}$} \\
\hline
\end{tabular}


guage development in infants with cleft lip and palate and as a result predictions of their developmental outcome cannot be accurate.

In the light of the wide spectrum of risk factors interacting at different times during the development of infants with cleft lip and palate, early intervention is implemented as secondary prevention of speech and language delays. As preschool language development has shown to be the single best predictor of a child's school success (Capute, Palmer \& Shapiro, 1987), the aim of early intervention is for comparable communication skills with peers as young as possible. In spite of the known risk factors, limited research has been conducted to provide a description of early communication profiles of infants with cleft lip and palate (Savage et al., 1994).

The aim of the study is to describe the early communication skills of a group of infants who attended an early intervention diagnostic clinic after being referred by the local Cleft Palate Clinic attached to the University of Pretoria or by professionals in private practice.

\section{METHODOLOGY}

The research methodology took the form of a descriptive survey as discrete data was derived from observational situations during the CHRIB assessments.

The subjects were recruited from the Clinic for High Risk Babies (CHRIB) at the Centre for Early Intervention in Communication Pathology, Department of Communication Pathology, University of Pretoria. CHRIB is a diagnostic facility of the early intervention programme for infants with disabilities or at-risk and their families and forms part of the centre's training activities and community service. A non-random non-probability sampling procedure was used to select the 44 subjects.

\section{DESCRIPTION OF SUBJECTS}

Due to the descriptive nature of the research methodology, the characteristics of the subjects are discussed in detail as this information is viewed to be of importance in the interpretation of the results and the conclusions reached (Savage, Neiman \& Reuter, 1994).

44 infants with cleft lip and palate and cleft palate only served as subjects for the survey, displaying a variety of six different cleft types (See Figure 1). Subjects with a cleft of the lip only were omitted from the study as they are generally not associated with speech and language disorders (Peterson-Felzone, 1989). An exceptional cleft type, namely a cleft of the lip and soft palate with an intact hard palate, occurred in one subject. This subject presented with extremely low birth weight $(1,37 \mathrm{~kg})$ and moderate prematurity ( 33 weeks gestation) as well.

The age of the subjects depended on their referral to CHRIB, which were usually after their primary surgery was completed (See Table 1). Subjects with associated anomalies, such as the subject with Down Syndrome, were referred much earlier. The majority of the subjects (93\%) had already received early communication intervention in the form of guidance and home programmes to the parents at the cleft palate clinic they were attending prior to their referral to CHRIB. The mean age of the subjects was 15 months which is considered as an ideal stage to conduct a comprehensive speech, language and hearing assessment and to continue with early communication intervention, as active team management usually de- creases after primary surgery has been completed and clients may be lost for follow-up. According to Table 1 the mean age of the subjects for soft palate repair was 5 months, while the mean age for lip and hard palate repair was 7 months.

As indicated in Table 1, the gender ratio displayed by the subjects does not reflect the accepted gender ratio of cleft lip and palate of twice as many males as females being affected. The omission of infants with a cleft lip only and the higher incidence of Pierre Robin Sequence among females could be related to the gender differences found in the present study, i.e. slightly more females $(54,5 \%)$ than males $(45,5 \%)$ with cleft lip and palate. Five of the seven subjects presenting with Pierre Robin Sequence were female, which is in agreement with literature findings of a female bias among these children (Amaratunga, 1989).

The subjects' birth weight was recorded separately for the Pierre Robin Sequence group and the rest of the subjects (See Table 1). Although the Pierre Robin Sequence sample was too small to statistically compare them with the rest of the subjects, their mean birth weight of $2,94 \mathrm{~kg}$ without prematurity should be noted. The subjects with Pierre Robin Sequence displayed a lower mean birth weight than the rest of the subjects, as well as a lower birth weight compared to the general population in developed countries. (Mean birth weight in developed countries: $3,4 \mathrm{~kg}$, ranging from $3,2 \mathrm{~kg}$ to $3,8 \mathrm{~kg}$, according to Turner, Douglas \& Cockburn, 1988). The finding of a lower birth weight than the average among Pierre Robin Sequence subjects can be compared to a study carried out by Laitinen, Heliövaara, Pere and Ranta (1994). This study also investigated the birth weight of Pierre Robin subjects and did not find a significant lower birth weight among them. The findings of the present study call for further research, as a better understanding of the characteristics of the Pierre Robin Sequence population is of great clinical importance.

Apart from the subjects' birth weight, the need for incubator care also emphasizes the subjects' vulnerability for biological risk conditions. $22,7 \%$ of the subjects were kept in an incubator during the neonatal period. The listing of associated conditions in Table 1 serves to provide a picture of the wide spectrum of major to minor associated anomalies and conditions present in $\mathbf{1 4}$ of the subjects.

The characteristics of the subjects' feeding difficulties directly after birth, as shown in Table 1, indicate that only 11 subjects required tube feeding. This implies that the subjects were referred for special care early enough to benefit from a jaw orthognathial suction and drinking plate (Bütow, 1995), which resulted in successful bottle and even breast feeding. Seven subjects succeeded in breast feeding, which is usually regarded as the least viable feeding option for infants with cleft palate.

The last two items in Table 1 concern the subjects' geographical and socio-economic backgrounds. $63,6 \%$ of the subjects lived in the Gauteng Province, a metropolitan area of which Pretoria is one of the largest cities. Most of the subjects were from middle income families, indicating that the study did not draw subjects from lower income families living in rural areas. This emphasises the inadequacies of tertiary health care to provide specialized services to infants with cleft lip and palate of families with limited resources to travel long distances to a cleft palate centre. At present the transformation of the national health system is to prioritize the development of primary health care 
and community based rehabilitation services in the rural areas (ANC, 1994).

Finally, the subjects' history of otitis media with effusion as a recurrent risk factor concerning their postnatal and later speech and language development, is presented in Figure $2.64 \%$ of the subjects had a history of recurrent otitis media with effusion. According to Figure 3 they were treated either by the insertion of ventilation tubes or by medication. Only $11 \%$ of the subjects received no treatment for otitis media, which implies that most of the parents were knowledgable about the management of middle ear infections.

In summary, the subjects were between 3 and 31 months old and displayed a variety of cleft types which were already repaired at the time of data collection. Their mean birth weight was within normal limits, but almost one third of the subjects either had associated anomalies and/or experienced biological risk conditions. Recurrent otitis media with effusion occurred in almost two thirds of the subjects. Most of the subjects were from middle income families living in a metropolitan area.

\section{ASSESSMENT PROTOCOL AND DATA COLLEC- TION}

Each subject underwent a comprehensive assessment of their hearing abilities, prespeech and language skills and general development based on a communication assessment protocol for cleft palate infants developed by Louw (1986) and adapted for CHRIB.

The hearing assessment was carried out using sound field behavioural observation audiometry for subjects un-

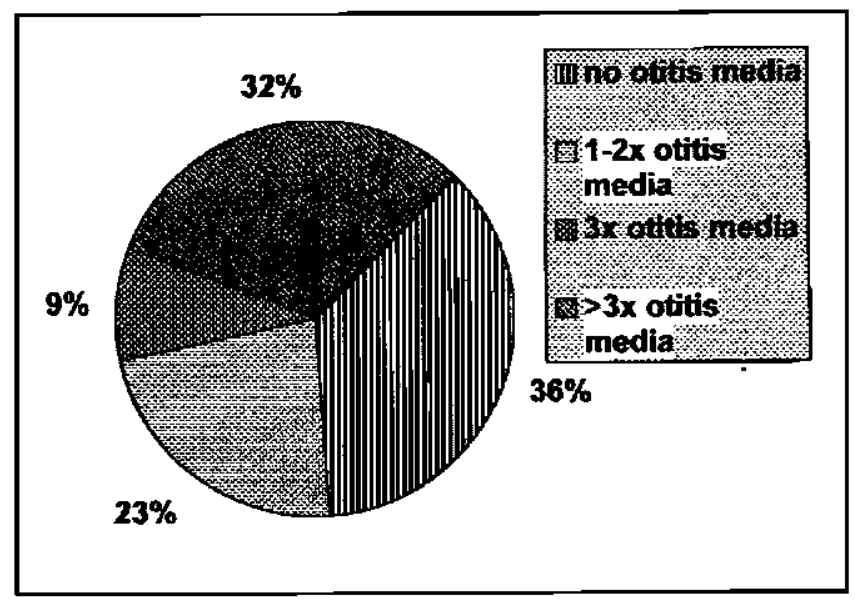

FIGURE 2: History of otitis media, $N=44$ der 5 months developmental age and sound field visual response audiometry for subjects older than 5 months developmental age with narrow band noise as the test stimulus. Immittance measurements were carried out for subjects of all ages. Data on all hearing measurements were collected by a qualified audiologist with experience in pedo. audiometric procedures. Normative data for different ages supplied by Northern and Downs (1984) was used to in. terpret the narrow band noise thresholds obtained from the subjects. Subjects with abnormal middle ear measurements were referred to an ear, nose and throat special. ist for follow-up.

The subjects' prespeech and language skills and general developmental skills were elicited and observed in a controlled play context, involving the infant and a speech. language therapist with the infant's parents as onlookers. Two qualified speech-language therapists with early in. tervention experience were involved in the data collection, one to elicit behaviour from the infant and the other to observe and record the data. Infant behaviours such as vocalizations and verbalizations were recorded and used as descriptive data while other behaviours were recorded using a developmental scale, the Developmental Assessment Schema (DAS) (Anderson, Nelson \& Fowler, 1978).

Data was analysed using descriptive statistics presented in the form of tables, pie charts and bar charts to provide means and ranges. The subjects' functioning on the DAS was statistically analysed using the Friedman two-way analysis of variance test with BMDP $3 \mathrm{~S}$ statistical software to determine significant differences between the 7 different subscales (level of significance: p_0.05).

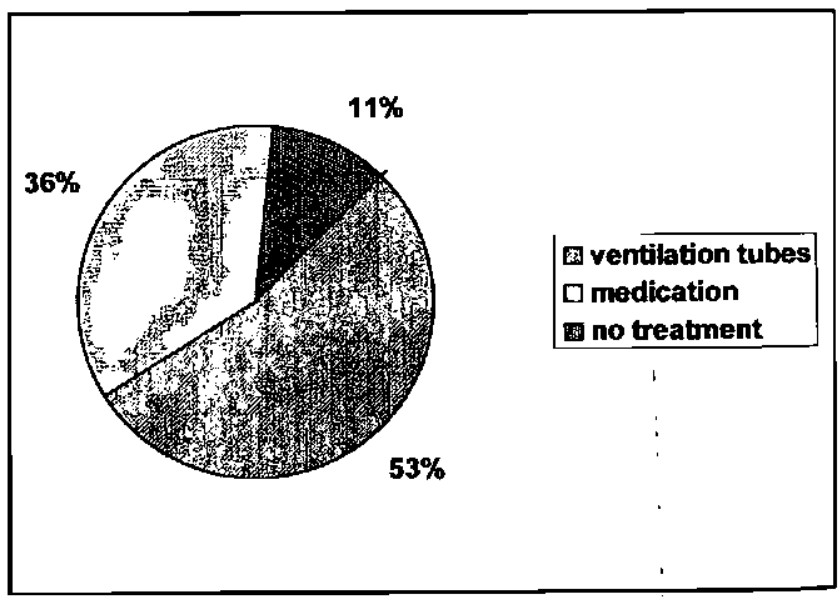

FIGURE 3: Treatment of otitis media, $\mathbf{N}=28$

TABLE 2. Results of Audiological Assessment, N=44

\begin{tabular}{|c|c|c|c|c|}
\hline & $\begin{array}{c}\text { Normal } \\
\text { thresholds }\end{array}$ & $\begin{array}{c}\text { Elevated } \\
\text { thresholds }\end{array}$ & $\begin{array}{l}\text { Sensorineural } \\
\text { hearing loss }\end{array}$ & Total \\
\hline \multirow[t]{2}{*}{ Hearing abilities } & $31(72 \%)$ & $11(26 \%)$ & $1(2 \%)$ & 44 \\
\hline & $\begin{array}{l}\text { Normal } \\
\text { middle ear } \\
\text { pressure }\end{array}$ & $\begin{array}{c}\text { Negative } \\
\text { middle ear } \\
\text { pressure }\end{array}$ & No test & Total \\
\hline $\begin{array}{l}\text { Middle ear } \\
\text { Functioning }\end{array}$ & $15(35 \%)$ & $11(26 \%)$ & $17(40 \%)$ & 44 \\
\hline
\end{tabular}




\section{RESULTS AND DISCUSSION}

The developmental profiles of the subjects are presented according to the assessment areas of hearing abilities, prespeech skills and the different subscales of the $D A S$ (Anderson, et al., 1978), i.e. expressive language, receptive language, personal-social, perceptual-cognitive, gross motor, fine motor, and self help skills.

\section{HEARING ABILITIES}

Table 2 indicates that $72 \%$ of the subjects displayed normal narrow band noise thresholds while $26 \%$ of the subjects showed elevated thresholds relative to mild hearing losses. One subject had a serious sensorineural hearing loss associated with prenatal syphilis exposure as well as a history of recurrent otitis media. At the time of testing she had ventilation tubes and no immittance measurements were carried out.

The narrow band noise thresholds of all subjects could be successfully determined by the proposed testing procedures. Not all subjects, however, could be tested for middle ear functioning. No immittance measurements were obtained of 17 subjects, as 15 subjects had ventilation tubes inserted following recurrent attacks of otitis media and two subjects would not cooperate for the immittance testing procedures to be carried out reliably.

Although $64 \%$ of the subjects (See Figure 2) had a history of recurrent otitis media with effusion, only $26 \%$ of the subjects evidenced negative middle ear pressure at the time of data collection. The relative small number of subjects found with abnormal middle ear functioning could be due to the treatment received prior to the testing (See Figure 3 ). The results also reveal the intermittent nature of the disease, indicating that reliable data on the occurrence of middle ear pathology among the subjects could only be obtained when data on both the history of the condition as well as immittance measurements were collected. This approach is also advocated by Grunwell, Sell and Harding (1993). It is therefore concluded that a far greater number of subjects experienced recurrent middle ear pathology than the $26 \%$ of subjects gleaned from the immittance measurements.

As indicated in Table 2, 11 subjects evidenced both elevated narrow band thresholds as well as negative middle ear measurements. Although not statistically analysed to establish a correlation, the results suggest that those subjects with abnormal middle ear measurements may have experienced some form of mild hearing loss. It is generally accepted that a conductive hearing loss of 15 to $40 \mathrm{~dB}$ may accompany the different forms of otitis media with effusion, such as serious otitis media, acute otitis media and chronic otitis media (Zarnoch \& Northern, 1989). The results emphasize the recurrent periods of auditory deprivation the subjects experienced during the critical window of opportunity for early language acquisition. These findings are in agreement with the studies of Blakely and Brockman (1995) and Russell and Grunwell (1993) who also found varying hearing levels associated with recurrent attacks of otitis media with effusion throughout infancy and early childhood as characteristic of their subjects with cleft lip and palate.

\section{PRESPEECH AND SPEECH DEVELOPMENT}

The majority of the subjects $(80 \%)$ displayed a limited phonetic repertoire in comparison with normal developmental levels as indicated in Table 3 . Observations revealed that the limited phonetic repertoires of the subjects were characterized by vowels and nasal fricatives, with a distinct absence of plosives and to a lesser degree, fricatives. These findings are in agreement with Chapman (1991) who found the number of consonants produced by 12 to 14 year old infants with cleft palate to be between 1 and 8 , whereas non-cleft subjects displayed phonetic repertoires of 2 to 16 consonants. The most frequently occurring consonants of these subjects were $/ \mathrm{m} /, \mathrm{n} /, / \mathrm{h} /$ and $/ \mathrm{w} /$.

It is interesting to note that despite the similar findings of limited phonetic repertoires, the subjects of the Chapman study (1991) had unrepaired cleft palates, whereas the present study utilized subjects with repaired cleft lip and palates. Although the mean age of the subjects for soft palate repair in the present study was relatively early, i.e. 5 months (See Table 1 ) most of the subjects displayed a limited phonetic repertoire. O'Gara and Logemann (1988) also found limited phonetic repertoires in their subjects with early palatal repair in comparison with normal development, suggesting that speech developmental constraints early in life continue to have an effect even after palatal repair.

Due to the limited expressive language displayed by the subjects, some as young as three months old, it was not possible to identify the resonance features of the prespeech utterances of $55 \%$ of the subjects (See Table 3 ). It was, however, possible to detect hypernasality, identified as nasal resonance on vowels and substitutions of oral plosives and fricatives for nasals, in the prespeech and speech patterns of $25 \%$ of the subjects. $20 \%$ of the subjects evidenced both normal phonetic repertoires as well as normal resonance features in their prespeech and speech development. Russell and Grunwell (1993) also found a percentage (12\%) of their subjects with cleft lip and palate to demonstrate normal phonetic development.

\section{RESULTS OF THE SUBSCALES OF THE DAS (ANDERSONET AL. 1978)}

Figure 4 provides the results of the 7 subscales of the $D A S$ (Anderson, et al. 1978). The results of the subject's receptive language development indicate that a total of

TABLE 3. Prespeech Development, $N=44$

\begin{tabular}{|l|c|c|c|c|}
\hline & Limited & Normal & Total \\
\hline Phonetic repertoire & $35(80 \%)$ & $9(20 \%)$ & 44 \\
\hline & Hypernasality & Normal & $\begin{array}{l}\text { Could not } \\
\text { establish }\end{array}$ & Total \\
\hline Speech resonance & $11(25 \%)$ & $9(20 \%)$ & $24(55 \%)$ & 44. \\
\hline
\end{tabular}


$64 \%$ of the subjects demonstrated average skills. In comparison, the subjects' expressive language development indicates a marked delay, with only $32 \%$ subjects displaying normal development. Table 4 provides the statistical analysis of the results, using the Friedman two way analysis of variance test to perform multiple comparisons. This test demonstrated a significant difference between the results on the DAS Expressive Language Scale (Anderson, et al. 197.8) and the other subscales, indicating a significant delay in the subjects' expressive language skills.

The nature of the subjects' expressive language delay as assessed by the DAS (Anderson, et al. 1978) includes delayed onset of vocalizations, babbling patterns, verbalizations, multiple word combinations as well as limited imitation skills. The subjects' delay in expressive language skills therefore includes more components of language abilities than the limited phonetic repertoires as discussed in the previous section. The present study therefore determined that the subjects displayed a delay in all components of expressive language development, indicating the extensive effects of the different risk factors on the subjects' early language development.

The expressive language delay without a concurrent delay in receptive language development found in the subjects is in agreement with studies by Louw (1986) and Sherer and D'Antonio (1995). Louw (1986) found a communication developmental delay in subjects under 12 months of age and Sherer and D'Antonio (1995) found delays in expressive language development in their subjects with cleft lip and palate when compared with subjects without clefts.

The subjects' age appropriate performance on personalsocial skills as measured on the DAS (Anderson, et al. 1978) signifies no delay in their nonverbal communication interaction skills and personal attachment behaviours. A study by Long and Dalston (1982) extensively investigated the gestural communication skills of 12 month old infants with cleft lip and palate and compared them with a normal control group of subjects. The findings indicated that no significant differences existed between the two

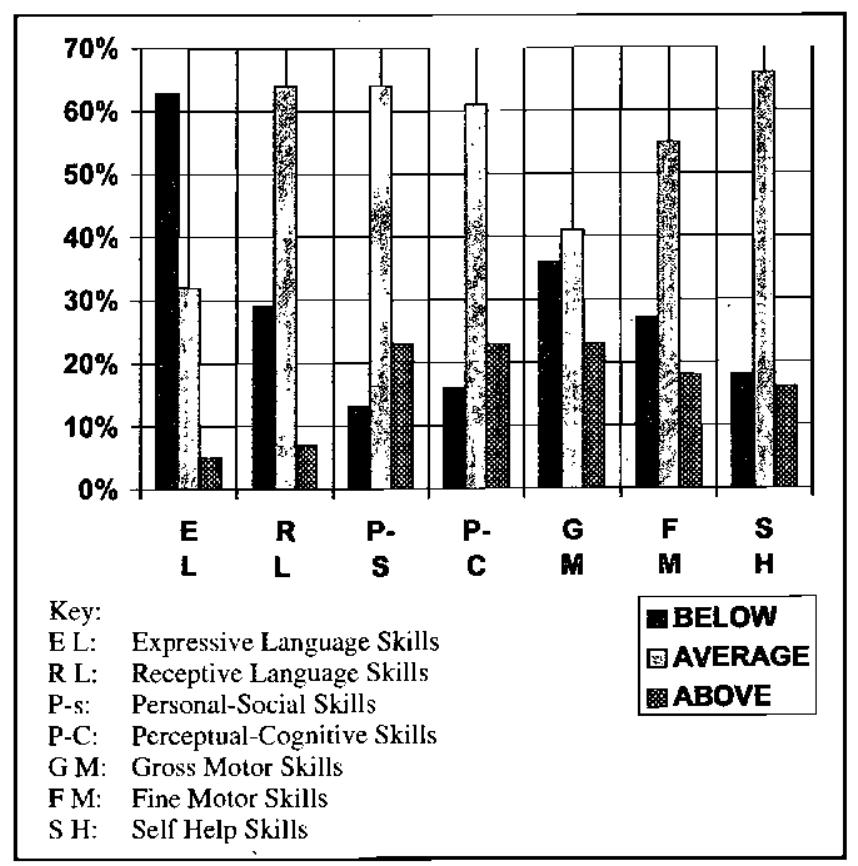

FIGURE 4: Profile of Development, N=44 groups, demonstrating that infants with cleft lip and palate experience no delay in the development of their nonverbal expressive language skills.

As receptive language ability and cognitive development are closely related in infancy (Lahey, 1988), the subjects' average functioning on the perceptual-cognitive subscale of the DAS (Anderson, et al. 1978) (See Figure 2), is viewed as part of their language developmental profile.

The subjects' language functioning in the present study was thus characterized by an incomplete phonetic repertoire, delayed expressive language development, but with age appropriate nonverbal communication interaction

TABLE 4. Multiple comparisons performed for Friedman two way analysis of variance test. Critical $Z$ values indicating a significant difference: $<3.04$ for overall alpha of $0.5{ }^{(* *)}$. Critical $Z$ values indicating a significant difference: $<2.82$ for overall alpha of $0.10\left(^{*}\right)$

\begin{tabular}{|c|c|c|}
\hline Comparisons & $\mathrm{Z}$ stat & Difference \\
\hline $\begin{array}{l}\text { Personal-Social } \\
\text { - Perceptual-Cognitive }\end{array}$ & 0.05 & -1.00 \\
\hline $\begin{array}{l}\text { Personal-Social } \\
\text { - Self Help }\end{array}$ & 0.89 & 18.00 \\
\hline Personal Social & & \\
\hline - Gross Motor & 1.53 & 31.00 \\
\hline Personal-Social & & \\
\hline - Fine Motor & 1.16 & 23.50 \\
\hline $\begin{array}{l}\text { Personal-Social } \\
\text { - Receptive Language }\end{array}$ & 2.42 & 49.00 \\
\hline $\begin{array}{l}\text { Personal-Social } \\
\text { - Expressive Language }\end{array}$ & $5.28^{* *}$ & 107.00 \\
\hline Perceptual-Cognitive & & \\
\hline $\begin{array}{l}\text { - Self Help } \\
\text { Perceptual-Cognitive }\end{array}$ & 0.94 & 19.00 \\
\hline - Gross Motor & 1.58 & 32.00 \\
\hline $\begin{array}{l}\text { Perceptual-Cognitive } \\
\text { - Fine Motor }\end{array}$ & 1.21 & 24.50 \\
\hline $\begin{array}{l}\text { Perceptual-Cognitive } \\
\text { - Receptive Language }\end{array}$ & 2.47 & 50.00 \\
\hline $\begin{array}{l}\text { Perceptual-Cognitive } \\
\text { - Expressive Language }\end{array}$ & $5.33^{* *}$ & 108.00 \\
\hline $\begin{array}{l}\text { Self Help } \\
\text { - Gross Motor }\end{array}$ & 0.64 & $\begin{array}{c}\vdots \\
13.00\end{array}$ \\
\hline Self Help & & \\
\hline - Fine Motor & 0.27 & 5.50 \\
\hline Self Help & & $!$ \\
\hline $\begin{array}{l}\text { - Receptive Language } \\
\text { Self Help }\end{array}$ & 1.53 & 31.00 \\
\hline - Expressive Language & $4.39^{* *}$ & 39.00 \\
\hline $\begin{array}{l}\text { Gross Motor } \\
\text { - Fine Motor }\end{array}$ & 0.37 & -7.50 \\
\hline $\begin{array}{l}\text { Gross Motor } \\
\text { - Receptive Language }\end{array}$ & 0.89 & 18.00 \\
\hline $\begin{array}{l}\text { Gross Motor } \\
\text { - Expressive Language }\end{array}$ & $3.75^{* *}$ & 76.00 \\
\hline $\begin{array}{l}\text { Fine Motor } \\
\text { - Receptive Language }\end{array}$ & 1.26 & 25.50 \\
\hline $\begin{array}{l}\text { Fine Motor } \\
\text { - Expressive Language } \\
\text { Receptive Language }\end{array}$ & $4.12 * *$ & 83.50 \\
\hline $\begin{array}{l}\text { Receptive Language } \\
\text { - Expressive Language }\end{array}$ & $2.86^{*}$ & 58.00 \\
\hline
\end{tabular}


skills as well as average receptive language functioning and perceptual-cognitive skills.

According to Figure $2,41 \%$ subjects displayed average gross motor development, while most of the subjects ( 55 $\%$ ) demonstrated average fine motor skills. Although most subjects' gross motor skills were below average development, the statistical analysis did not reveal a significant difference between the various subscales to indicate a delay. Not withstanding that research on the motor development of infants with cleft lip and palate is limited, Savage et al. (1994) also suggest delayed motor development in 6 to 12 month old subjects as measured on the Bayley Scales of Infant Development.

The results of the present study partly correlate with the findings of Louw (1986) who determined delayed motor development in $44 \%$ of subjects, 0 to 12 months of age. The present study, utilizing older subjects, found fewer subjects $(36 \%)$ functioning below average for motor development. Longitudinal data is, however, needed to determine the developmental motor patterns of infants with cleft lip and palate.

The last subscale of the DAS (Anderson, 1978) deals with self help skills, i.e. skills related to feeding, dressing and toiletting. As a group the subjects displayed age appropriate developmental levels, indicating that feeding problems experienced before surgery were largely overcome by the time of data collection.

In summary, the subjects' functioning on the 7 different subscales of the DAS (Anderson, et al. 1978), were as follows: The majority of the subjects displayed age appropriate functioning in receptive language, perceptual-cognitive, personal-social and self help skills. Their fine and gross motor skills evidenced lower levels of functioning, although these were not found to be statistically significant. The only developmental area in which the subjects as a group displayed a significant delay, was their expressive language skills.

\section{CONCLUSION}

A characteristic communication developmental profile of the subjects emerged from the results. Certain components of their language abilities revealed strong points, i.e. nonverbal communication interaction and receptive language skills, while an expressive language delay and a limited phonetic repertoire demonstrated their weak points. The subjects' communication profile should further be viewed against the broader developmental perspective of their age appropriate cognitive and self help skills, but a slight delay in motor development was present. As the subjects had already benefitted from a communication intervention programme and sufficient management of middle ear pathology since birth, the results cannot be generalised, especially not to infants with cleft lip and palate from disadvantaged communities in South Africa. In order to provide effective early intervention services in South Africa for all infants with cleft lip and palate, further research is required. The effects of the risk factors associated with disadvantaged environmental circumstances on the communication development of these infants need to be determined.

Previous studies have extensively investigated the phonetic and phonological development of infants with cleft lip and palate (Chapman, 1991; Chapman \& Hardin, 1992; Lohmander-Agerskov, Soderpalm, Friede, Persson \& Lilja,
1994; Jansonius-Schultheiss, 1989; O'Gara \& Logemann, 1988; O'Gara, Logemann \& Rademaker, 1994; Russell \& Grunwell, 1993), but much less focus was placed on the nature of these infants' language development. Although the present study describes the nature of the subjects' expressive language delays, further research is required to provide clarity on the interaction between risk factors and language development. The study points to the need for widely available appropriate early intervention programmes for infants with cleft lip and palate. Despite the dearth of research, however, some early language intervention programmes and protocols for infants with cleft lip and palate advocate a holistic approach and include all components of language development (Langlois \& Nowak, 1990; Lynch, Brookshire \& Fox, 1993; Scheuerle in Bzoch, 1989). Although these programmes are widely applied, they have to be adapted to meet the needs of the unique South African context.

The current study provided a characteristic communication profile of the subjects as a group, but the diversity of the individual subjects should be emphasized. The presence of Pierre Robin Sequence as a vulnerable group for hearing loss (Handzic, Bagatin, Subotic \& Cuk, 1995), associated anomalies and malformations (Sprintzen, 1988) and mental retardation among the subjects (CauetteLaberge, Bayet \& Larocque, 1994) calls for individualized language intervention programmes with full parental involvement and committed transdisciplinary teamwork. The incidence of associated conditions such as Down Syndrome and severe sensorineural hearing loss (See Table 1) emphasizes the need for specialized knowledge in more than one field to meet the needs of infants with multiple disabilities. The intermittent hearing loss caused by recurrent otitis media with effusion which a number of subjects experienced, requires periodic monitoring of hearing at least every six months (ASHA, 1994).

As a first attempt to describe a section of the cleft lip and palate population, the study provided useful information. Expanded research is, however, necessary to provide information on which to base context relevant services. Efforts must be directed towards expanding early communication intervention services to reach all infants with cleft lip and palate and their families.

Infants with cleft lip and palate represent a diverse population with various risk factors continuously influencing their communication development. They are particularly at-risk for expressive language delays. This poses great challenges for individualized early communication intervention services to them and their families. Based on the results of the present study, the preferred approach is the implementation of regular early intervention sessions, commencing before surgery, fully involving the parents, with a curriculum emphasis not only on monitoring hearing abilities and facilitating expressive language development, but also on all components of language and general development.

\section{REFERENCES}

Amaratunga, N.A. de S. (1989). A Comparative Clinical Study of Pierre Robin Syndrome and Isolated Cleft Palate. British Journal of Oral and Maxillofacial Surgery, 27, 451-458.

ANC. (1994). A National Health Plan for South Africa. Johannesburg: ANC.

Anderson, D. Nelson, J. \& Fowler, S. (1978). Developmental assessment schema. In Northcott, W.H. (Ed.), Curriculum 
Guide: Hearing Impaired Children ( 0.3 years) and their Parents. Washington, DC: The Alexander Bell Association for the Deaf, Inc.

ASHA. (1994). Joint Committee on Infant Hearing. 1994 Position Statement. ASHA, December, 38-41.

Blakely, R.W. \& Brockman, J.H. (1995). Normal Speech and Hearing by age 5 as a Goal for Children with Cleft Palate: A Demonstration Project. American Journal of Speech-Language Pathology, 4(1), 25-32.

Bütow, K-W. (1995). Treatment of Facial Clef Deformities. An Illustrated Guide. St. Louis: Ishiyalcu Euro America, Inc.

Capute, A.J., Palmer, F.B. \& Shapiro, B.K. (1987). Using language to track development. Patient Care, November, 60-71.

Cauette-Laberge, L., Bayet, B. \& Laroque, Y. (1994). The Pierre Robin Sequence: Review of 125 Cases and Evolution of Treatment Modalities. Plastic and Reconstructive Surgery, 93(5), 934-942.

Chapman, K.L. (1991). Vocalizations of Toddlers with Cleft Lip and Palate. Cleft Palate Cranio-facial Journal, 28(2), 172178.

Chapman, K.L. \& Hardin, M.A. (1992). Phonetic and Phonological Skills of Two-year-olds with Cleft Palate. Cleft Palate Craniofacial Journal, 29(5), 435-443.

Goldman, J.L., Martinez, S.A. \& Ganzel, T.M. (1993). Eustachian Tube Dysfunction and its Sequelae in Patients with Cleft Palate. Southern Medical Journal, 86(11), 1236-1237.

Grunwell, P., Sell, D. \& Harding, A. (1993). Describing Cleft Palate Speech. In Grunwell, P. (Ed.), Analysing Cleft Palate Speech. London: Whurr Publishers Ltd.

Handzic, J., Bagatin, M. Subotic, R. \& Cuk, V. (1995). Hearing Levels in Pierre Robin Syndrome. Cleft Palate-Craniofacial Journal, 32(1), 30-36.

Jansonius-Schultheigs, K. (1989). Phonological Development in two year old Cleft Lip and Palate Toddlers. Proceedings: 6th International Congress on Cleft Palate and Related Craniofacial Anomalies, 29. Jerusalem.

Laitinen, S., Heliövaara, A., Pere, A. \& Ranta, R. (1994). Growth in Children with Pierre Robin Sequence and Isolated Cleft Palate. Acta Paediatrics, 83, 1161-1164.

Lahey, M. (1988). Language Disorders and Language Development. New York: Macmillan Publishing Company.

Langlois, A. \& Nowak, B.R. (1990). The First year of a Child with Cleft Palate: An Approach to Facilitate Communication Development. Infants and Young Children, 2(4), 34-50.

Lohmander-Agerskov, A., Soderpalm, E., Friede, H., Persson, E. \& Lilja, J. (1994). Pre-speech in Children with Cleft Lip and Palate or Cleft Palate Only: Phonetic Analysis Related to Morphologic and Functional Factors. Cleft Palate-Craniofacial Journal, 31(4), 271-279.
Long, N.V. \& Dalston, R.M. (1982). Gestural communication in twelve-month-old cleft lip and palate children. Cleft Palate Journal, 19(1), 57-61.

Louw, B. (1986). Swart Babas met Gesplete Lip en Verhemelte: 'n Morfofunksionele Studie. Unpublished D Phil Dissertation: University of Pretoria.

Lynch, J.I. (1986). Language of Cleft Infants: Lessening the Risk of Delay through Programming. Seminars in Speech and Language, 7(3), 255-268.

Lynch, J.I., Brookshire, B.L. \& Fox, D.R. (1993). A Curriculum for Infants and Toddlers with Cleft Palate. Developing Speech and Language. Austin: Pro-ed.

Northern, J.L. \& Downs, M.P. (1984). Hearing in Children. Baltimore: Williams \& Wilkens.

O'Gara, M.M. \& Logemann, J.A. (1988). Phonetic Analysis of the Speech Development of Babies with Cleft Palate. Cleft Palate Journal, 25(2), 122-134.

O'Gara, M.M., Logemann, J.A. \& Rademaker, A.W. (1994). Phonetic Features by Babies with Unilateral Cleft Lip and Palate. Cleft Palate-Craniofacial Journal, 31(6), 446-451.

Peterson-Felzone, S.J. (1989). Speech disorders related to craniofacial structural defects. In Northern, J.L. (Ed.), Siudy Guide for the Handbook of Speech-language Pathology and Audiology, Toronto: B.C. Decker Inc.

Russell, J \& Grunwell, P. (1993). Speech Development in Children with Cleft Palate. In Grunwell, P. (Ed.), Analysing Cleft Palate Speech. London: Whurr Publishers Ltd.

Samerhoff, A.J. (1986). Environmental context of child development. The Journal of Pediatrics, 109(1), 192-200.

Savage, H.E., Neiman, G.S. \& Reuter, J.M. (1994). A Developmental Perspective on Assessment of Infants with Clefts and Related Disorders. Infant-Toddler Intervention, $4(3), 221-234$.

Scherer, N.J. \& D'Antonio, L.L. (1995). Parent Questionnaire for Screening Early Language Development in Children with Cleft Palate. Cleft Palate-Craniofacial Journal, 32(1), 7-13.

Scheuerle, J. (1989). Stimulating language development in infants and toddlers with cleft palate. In Bzoch, K.R. (Ed.), Communicative Disorders Related to Cleft Lip and Palate. Boston: Little Brown and Company.

Shprintzen, R.J. (1988). Pierre Robin, Micrognathia and Airway Obstruction: The Dependency of Treatment on Accurate Diagnosis. International Anesthesiology Clinics, 26(1), 64-71.

Turner, T.L., Douglas, J. \& Cockburn, F. (1988). Graig's Care of the Newly Born Infant. Edinburgh: Churchill Livingstone.

Zarnoch, J.M. \& Northern, J.L. (1989). Audiologic Manifestations. In Northern, J.L. (Ed.), Study Guide for the Handbook of Speech-language Pathology and Audiology. Toronto: B.C. Decker Inc. 